To the Editors

\title{
Neurocognitive skills in children with congenital hypothyroidism attending the endocrine clinic of the Professorial Unit of the Lady Ridgeway Hospital for Children, Colombo
}

\author{
*Samanmali P Sumanasena ${ }^{1}$, Nalika Gunawardena ${ }^{2}$, Buddini Dissanayake ${ }^{3}$, Supun Dilanka ${ }^{3}$, Shamya de \\ Silva ${ }^{4}$
}

Sri Lanka Journal of Child Health, 2017; 46(1): 101

DOI: http://dx.doi.org/10.4038/sljch.v46i1.8233

(Key words: Congenital hypothyroidism, neurocognitive skills, school aged children)

I wish to bring to your kind notice that there was a concern raised by a colleague regarding the above article which was published in pages 94 to 101 of the June 2016 issue of the Sri Lanka Journal of Child Health. The concern was the following sentence in the conclusion as it appears in the abstract as well as the main article:

"There was no significant correlation between the neurocognitive scores and age at diagnosis, initial TSH levels, thyroxine commencement dose or number of clinic visits in the first year".

While our intention was never to give an impression that low commencement dose of thyroxine or late detection of the condition did not impact the neurocognitive performance of the children with congenital hypothyroidism, according to my colleague the article reads so. If the reader looks at the results carefully, it is very obvious that the large majority of these children presented very late and the mean age at presentation was more than 2 years, and the majority were started on a dose well below the recommended dose of thyroxine. Also the sample of children was only 23 . Hence we could not establish any relationship between these factors and the outcomes.

From the researcher's point of view, I do not think anybody should get an impression of a research by only reading the final sentence of the conclusion. However, if that is how a reader interprets the results of this study, I wish to request from you to kindly publish a correction to this last sentence in the conclusion within the abstract and the main text as follows:

"There was no significant correlation between the neurocognitive scores and age at diagnosis, initial TSH levels, thyroxine commencement dose or number of clinic visits in the first year. These findings are most probably due to the small number of participants in this study and because the majority were commenced on suboptimal doses of thyroxine later in infancy".

\author{
Samanmali P. Sumanasena \\ Senior Lecturer \& Honorary \\ Consultant Paediatrician, \\ Disability Studies Department, \\ Faculty of Medicine, Ragama \\ *Correspondence: samanmalis@yahoo.com
}

\section{Editorial Comment}

There is no doubt that there are three crucial considerations in the treatment of congenital hypothyroidism.

1. That a firm diagnosis is made as early as possible, ideally in the immediate newborn period.

2. Optimal treatment, under expert supervision, is provided as soon as the diagnosis is made.

3. Regular follow-up and close monitoring is carried out from then onwards.

In these respects, the journal is duty-bound to recommend that Newborn Screening for Hypothyroidism is promulgated and propagated in the best possible fashion in Sri Lanka.

The Editors are aware that such a Screening Programme has now been initiated by the authorities. They believe that scrupulous attention to all details should be ensured to provide the best possible treatment to these children with congenital hypothyroidism to prevent or at least greatly minimise the possible long-term sequelae. 